\title{
Polymer-encapsulated colorful Al pigment with high NIR and UV reflectance and their application in textiles
}

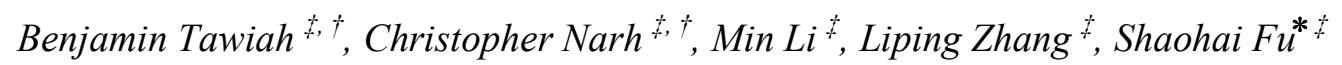

${ }^{\dagger}$ Key Laboratory of Eco-Textile, Jiangnan University, Ministry of Education, Wuxi, Jiangsu 214122, China

${ }^{\dagger}$ Kwame Nkrumah University of Science and Technology, Private Mail Bag - Kumasi, Ghana

*Corresponding author’s email: shaohaifu@hotmail.com

Table S1: Effect of baking temperature on $\mathrm{K} / \mathrm{S}$ value ${ }^{1}$.

\begin{tabular}{|l|l|l|l|l|l|}
\hline $\begin{array}{l}{ }^{2} \text { Baking temperature } \\
\left({ }^{\circ} \mathrm{C}\right)\end{array}$ & 120 & 140 & 150 & 160 & 170 \\
\hline K/S value & 5.12 & 5.18 & 5.89 & 5.20 & 5.18 \\
\hline
\end{tabular}

Note: ${ }^{1}$ Note: coating thickness $30 \mu \mathrm{m}$

${ }^{2}$ Baking time: 3 minutes. 